We welcome letters to the Editor concerning articles which have recently been published. Such letters will be subject to the usual stages of selection and editing; where appropriate the authors of the original article will be offered the opportunity to reply.

Letters should normally be under $\mathbf{3 0 0}$ words in length, doublespaced throughout, signed by all authors and fully referenced. The edited version will be returned for approval before publication.

(C)2005 British Editorial Society of Bone and Joint Surgery \$2.00 J Bone Joint Surg [Br] 2005;87-B:1700-2.

\section{Fatal haemorrhage following a low-energy fracture of the pubic ramus}

Sir,

I read with interest the article in the September 2005 issue by Coupe et $\mathrm{al}^{1}$ entitled 'Fatal haemorrhage following a low-energy fracture of the pubic ramus'. It highlights a potentially important problem, of which I had a similar experience as a trainee. The patient was also an elderly female, on warfarin, who had suffered a minimally-displaced fracture of the ramus. While lying on the stretcher in the emergency department, her abdomen became increasingly distended and the CT scan revealed a very large haematoma. Fortunately, this patient survived after administration of blood and fresh-frozen plasma. However, it was not an easy course in hospital. Such cases illustrate the potential difficulty in managing these patients, particularly in times of surgical bed shortages and the reluctance to admit and treat patients on a surgical service. The majority of these patients require analgesia and early mobilisation, but we are acutely aware of the dangers posed to these patients who are on anticoagulant therapy and have what appears to be an innocuous injury.

doi:10.1302/0301-620X.87B12.17239

\section{P. GRAHAM}

University of Manitoba, Winnipeg, Canada.

1. Coupe NJ, Patel SN, McVerry S, Wynn-Jones CH. Fatal haemorrhage following a low-energy fracture of the pubic ramus. J Bone Joint Surg [Br]2005;87-B:1275-6.

\section{Criteria for arthroscopic treatment of anterior instability of the shoulder}

Sir,

We read with interest the article by Calvo, Granizo and Fernándex-Yruegas ${ }^{1}$ in the May 2005 issue entitled 'Criteria for arthroscopic treatment of anterior instability of the shoulder' and would like to raise the following points. First, the authors state that "Open techniques have a lower failure rate, but carry a risk of restriction of movement and a longer period of recovery". ${ }^{1}$ However, this rationale in support of arthroscopic surgery is not sup- ported by the evidence and is, in fact, contradicted later in the paper. The study by Pagnani and Dome ${ }^{2}$ is cited in their discussion. It showed that in American football players open surgery can restore stability while maintaining a good range of movement. Calvo et $\mathrm{al}^{1}$ describe their post-operative regime following arthroscopic surgery. The period of recovery recommended is not shorter than the post-operative regime recommended following open surgery. ${ }^{3}$

Secondly, the paper reports a recurrence rate of $18 \%$, a figure which is similar to other studies and which the authors admit "is not acceptable". This rate is substantially higher than with open repairs which have a recurrence rate of between $6.3 \%$ and $11.7 \% .^{4}$

Finally, despite the high rate of failure of arthroscopic surgery, the authors maintain their enthusiasm for the procedure, stating that it "has clear advantages in comparison with open surgery" and that "these objective benefits are supported by the high degree of satisfaction reported by our patients, most of whom recognised that they would choose arthroscopic instead of open stabilisation again, even those with recurrent post-operative instability". The authors' enthusiasm for the procedure seems to have communicated itself to the patients, as six patients with recurrent instability still rated their result as good or excellent. We wonder how they would have rated their result had the operation been successful. The authors also state that only one in 65 patients declined arthroscopic surgery at the outset. We feel that the patients' and doctors' enthusiasm for arthroscopic shoulder stabilisation is not supported by the evidence.

doi:10.1302/0301-620X.87B12.16896

\section{S. A. SEXTON}

C. PEARCE

D. M. RICKETTS

Princess Royal Hospital,

Haywards Heath, UK.

1. Calvo E, Granizo JJ, Fernández-Yruegas D. Criteria for arthroscopic treatment of anterior instability of the shoulder: a prospective study. J Bone Joint Surg [Br] 2005;87-B:677-83.

2. Pagnani MJ, Dome DC. Surgical treatment of traumatic shoulder instability in American football players. J Bone Joint Surg [Am] 2002;84-A:711-15.

3. Writh MA, Blatter G, Rockwood CA. The capsular imbrication procedure for recurrent anterior instability of the shoulder. J Bone Joint Surg [Am] 1996;78-A:246-59.

4. Robinson CM, Dobson RJ. Anterior instability of the shoulder after trauma. J Bone Joint Surg [Br] 2004;86-B:469.

\section{Authors' reply:}

Sir,

We thank Messrs Sexton and Ricketts for their interest in our article.

There is clearly enthusiasm for the arthroscopic treatment of shoulder instability. There is evidence that arthroscopy reduces morbidity and that it achieves a better cosmetic result, as well as a better overall range of movement and function. ${ }^{1,2}$ These benefits are confirmed by patients. 
The degree of patient satisfaction in our study was very high, even in those cases where there was recurrent post-operative instability. Our criteria of failure were strict, and the majority of patients in whom the procedure was considered to have failed had improved their level of stability sufficiently so as not to interfere with their activities. In spite of these advantages, the major drawback of arthroscopic shoulder stabilisation is its higher rate of recurrence compared with open surgery. Technical improvements, the repair of all joint abnormalities which potentially contribute to instability and the proper selection of candidates are key issues in improving results.

Kim et $\mathrm{al}^{3}$ and Gartsman, Roddey and Hammerman ${ }^{4}$ reported recurrence rates comparable with open techniques using bone anchors and addressing all intra-articular pathology. In our series only long-term cases, operated on with the multiple suture technique, were included in order to make the patient series homogeneous. Therefore, $18 \%$ should not be considered the usual recurrence rate of arthroscopic shoulder stabilisation. Regarding patient selection, our study establishes a clear system to improve the results of arthroscopic shoulder stabilisation. Arthroscopy has achieved a high level of acceptance, and enthusiasm for its application in shoulder instability is based on clinical evidence. It is our responsibility as orthopaedic surgeons to do our best to improve the results.

doi:10.1302/0301-620X.87B12.16897

E. CALVO, MD

J. J, GRANIZO, MD

D. FERNÁNDEZ-YRUEGAS, MD

Fundanción Jiménez Diaz,

Madrid, Spain.

1. Green MR, Christensen KP. Arthroscopic versus open Bankart procedures: a comparison of early morbidity and complications. Arthroscopy 1993;9:371-4.

2. Karlsson J, Magnusson L, Ejerhed L, et al. Comparison of open and arthroscopic stabilization for recurrent shoulder dislocation in patients with a Bankart lesion. Am J Sports Med 2001;29:538-42.

3. Kim SH, Ha KI, Cho YB, Ryu BD, Oh I. Arthroscopic anterior stabilization of the shoulder: two to six-year follow-up. J Bone Joint Surg [Am]2003;85-A:1511-18.

4. Gartsman GM, Roddey TS, Hammerman SM. Arthroscopic treatment of anteriorinferior glenohumeral instability: two to five-year follow-up. J Bone Joint Surg [Am] 2000;82-A:991-1003.

\section{Internal fixation versus hemiarthroplasty for displaced fractures of the femoral neck in elderly patients with severe cognitive impairment}

Sir,

I read with interest the article in the April 2005 issue by Blomfeldt et $\mathrm{al}^{1}$ entitled 'Internal fixation versus hemiarthroplasty for displaced fractures of the femoral neck in elderly patients with severe cognitive impairment'.

In their study, the authors reported an overall rate of failure of $41 \%$ in the internal fixation group, which although comparable with other similar series ${ }^{2,3}$ is unacceptably high. Among the survivors at two years, there was a very high rate of re-operation in the internal fixation group (nine of 17) compared with the hemiarthroplasty group (three of 18). The high rate of nonunion may be partly attributed to non-compliance of the patients to remain non-weight-bearing on the affected hip after internal fixation. On the other hand, hemiarthroplasty requires no such compliance and dislocation of the prosthesis is very uncommon (no dislocation in the present series). The reason for sudden deterioration in the health-related quality of life of the hemiarthroplasty group between one and two years after surgery remains unclear. Other studies have shown that a cemented hemiarthroplasty is associated with much less pain and better mobility compared with uncemented prostheses. ${ }^{4}$ The risk of periprosthetic fractures has also been shown to be less after cemented rather than uncemented hemiarthroplasty. ${ }^{5}$ However, cemented hemiarthroplasty does carry a slightly higher risk of deep infection. ${ }^{2}$

The authors may have reached a different conclusion had they concentrated on the number of patients requiring re-operation rather than on the number of revision procedures needed in each group. Although uncemented hemiarthroplasty may not be ideal for all elderly patients, there is no doubt that cemented hemiarthroplasty is a better option in the majority of cases as the outcome is more predictable and the risk of failure requiring reoperation is much smaller. A randomised trial would certainly help to resolve the controversy. doi:10.1302/0301-620X.87B12.16970

D. ABBAS, MS Orth, MSc, FRCS

Milton Keynes General Hospital,

Milton Keynes, UK.

1. Blomfeldt R, Törnkvist H, Ponzer S, Söderqvist A, Tidermark J. Internal fixation versus hemiarthroplasty for displaced fractures of the femoral neck in elderly patients with severe cognitive impairment. J Bone Joint Surg [Br] 2005;87-B:523-9.

2. Parker MJ, Khan RJK, Crawford J, Pryor GA. Hemiarthroplasty versus internal fixation for displaced intracapsular hip fractures in the elderly. J Bone Joint Surg [Br] 2002;84-B:1150-5

3. Rogmark C, Carlsson A, Johnell O, Sernbo I. A prospective randomised trial of internal fixation versus arthroplasty for displaced fractures of the neck of the femur: functional outcome for 450 patients at two years. J Bone Joint Surg [Br] 2002;84B:183-8.

4. Parker MJ, Gurusamy K. Arthroplasties (with and without bone cement) for proximal femoral fractures in adults. Cochrane Database Syst Rev 2004;2:1706.

5. Foster AP, Thompson NW, Wong J, Charlwood AP. Periprosthetic femoral fractures: a comparison between cemented and uncemented hemiarthroplasties. Injury 2005:36:424-9.

\section{Author's reply:}

Sir,

We thank Mr Abbas for his valuable comments. First, we would like to emphasise that the aim of our paper was not to compare hemiarthroplasty with internal fixation in the treatment of displaced fractures of the femoral neck in the elderly population in general. The aim was to evaluate these treatments in a highly selected group of patients with severe cognitive impairment. The results in both groups with a very high rate of mortality, significant deterioration in activities of daily living, reduced walking ability and health-related quality of life, show the major impact on outcome in the presence of severe cognitive dysfunction. These results are also supported by the only previous study on the same selected group of patients by van Dortmont et al. ${ }^{1}$

The high rate of complications after internal fixation of displaced fractures of the femoral neck is not unique to this trial nor to this patient cohort. Almost all prospective trials with at least a two-year follow-up have a rate of complications of fracture healing of between $35 \%$ and $50 \%$. $^{2,3}$ In our opinion, it is not justifiable to recommend post-operative non-weight-bearing in elderly patients after a hip fracture, especially not in this group of patients, which by definition was non-compliant.

At the start of this trial, the uncemented Austin Moore prosthesis was still an accepted implant in Sweden for this category of patient and is still recommended by some authors for the majority of elderly patients with displaced fractures of the femoral neck. ${ }^{4}$ 
We share Mr Abbas' opinion that a cemented prosthesis would probably create less pain and better mobility; an opinion also supported by a recent meta-analysis. ${ }^{5}$ However, the cementing procedure may increase the risk of serious peri-operative complications, especially in this group of fragile patients. ${ }^{6}$

We chose to report both the number of patients requiring reoperation and the number of such procedures needed in each group. The total number of revision procedures needed reflects the severity of the complications and also the burden for the health care system. The tendency for a reduced number of re-operated patients in the hemiarthroplasty group, although not confirmed in the number of re-operations, must be balanced against the better outcome regarding hip function and health-related quality of life in the internal fixation group. Clinicians may come to a different conclusion in this aspect. Our conclusion is that there does not seem to be any obvious advantage in performing an uncemented Austin Moore hemiarthroplasty compared with internal fixation in patients with severe cognitive dysfunction.

We agree with Mr Abbas that the role of a cemented hemiarthroplasty in this patient group needs to be evaluated in future trials. We are currently performing a randomised, controlled trial comparing a modern cemented hemiarthroplasty with internal fixation using the same inclusion criteria as in the present paper. doi:10.1302/0301-620X.87B12.16971

J. TIDERMARK, MD, PhD

Stockholm Söder Hospital,

Stockholm, Sweden.

1. van Dortmont LM, Douw CM, van Breukelen AM, et al. Cannulated screws versus hemiarthroplasty for displaced intracapsular femoral neck fractures in demented patients. Ann Chir Gynaecol 2000;89:132-7.

2. Lu-Yao GL, Keller RB, Littenberg B, Wennberg JE. Outcomes after displaced fractures of the femoral neck: a meta-analysis of one hundred and six published reports. J Bone Joint Surg [Am] 1994;76-A:15-25

3. Tidermark J. Quality of life and femoral neck fractures. Acta Orthop Scand Suppl 2003;74:1-42.

4. Parker MJ, Khan RJ, Crawford J, Pryor GA. Hemiarthroplasty versus internal fixation for displaced intracapsular hip fractures in the elderly: a randomised trial of 455 patients. J Bone Joint Surg [Br] 2002;84-B:1150-5.

5. Parker MJ, Gurusamy K. Arthroplasties (with and without bone cement) for proximal femoral fractures in adults. Cochrane Database Syst Rev 2002;2:1706.

6. Parvizi J, Holiday AD, Ereth MH, Lewallen DG. The Frank Stinchfield Award: sudden death during primary hip arthroplasty. Clin Orthop 1999;369:39-48.

\section{Pregnancy and childbirth after total hip arthroplasty}

Sir,

We read with interest the article by Sierra, Trousdale and Cabanela ${ }^{1}$ in the January 2005 issue entitled 'Pregnancy and childbirth after total hip arthroplasty'.

This study is one of the largest series which focuses on pregnancy and childbirth after total hip arthroplasty (THA). Data were collected retrospectively with a high response rate of $76 \%$. Within a group of 47 women who had their first child after THA, 30 had a successful vaginal delivery with no increased time to revision compared with those who had a Caesarean. However, it is not clear whether there is a difference between elective Caesarean and an emergency or secondary Caesarean with the primary intention to deliver vaginally. It is known that the morbidity of elective Caesarean is quite different from secondary Caesarean. Therefore it is likely that this will influence the outcome on arthroplasty, especially when Caesarean is performed because of a delayed second stage. Unfortunately, the authors do not show the exact number of revisions of those 47 women.

Furthermore, we wondered whether the risk of revision after THA is a correct parameter of outcome, since it does not accurately demonstrate the life of arthroplasties. The clinical issues are first, whether the life of an arthroplasty will change when women have one or more children (or indeed none) and secondly, whether an elective Caesarean increases the life of the arthroplasty compared with a vaginal delivery.

doi:10.1302/0301-620X.87B12.16913

\section{B. GINSEL}

Radbound University,

Nijmegen, The Netherlands.

J. M. A. PIJNENBORG

Tweesteden Hospital,

Tilburg, The Netherlands.

1. Sierra RJ, Trousdale RT, Cabanela ME. Pregnancy and childbirth after total hip arthroplasty. J Bone Joint Surg [Br] 2005;87-B:21-4.

\section{Authors' reply:}

Sir,

We thank Drs Ginsel and Pijnenborg for their interest in our article.

Regarding their first statement, the reasons for Caesarean were specified in the paper. Eleven patients underwent Caesarean for obstetric reasons and there were six in whom the operation was elective. With so few statistics it was impossible to assess the effect of elective $v s$ secondary Caesarean on the outcome of the arthroplasty. The total number of revision hip arthroplasties performed on the 47 women who had successful pregnancies after arthroplasty was 24 , which is also stated in our paper.

They also question the use of revision of the arthroplasty as an appropriate parameter of outcome. We think it is the most objective recognised parameter. While revision is an objective endpoint, it is possible that there may be patients with loose total hips which have not been revised, who have been omitted from the survey. However, it is likely that these patients would have pain and that is why we included groin pain in our survey as another endpoint.

Our paper could not address the issue of whether an elective Caesarean increases the life of the arthroplasty compared with a vaginal delivery because we did not have sufficient data to carry out the appropriate statistical comparisons.

doi:10.1302/0301-620X.87B12.16914

\section{R. J. SIERRA, MD}

R. T. TROUSDALE, MD

M. E. CABANELA, MD

Mayo Clinic,

Rochester, Minnesota, USA. 